\title{
INTEGRATING MINI-MOOCS INTO STUDY PROGRAMS IN HIGHER EDUCATION DURING COVID-19. FIVE PILOT CASE STUDIES IN CONTEXT OF THE OPEN VIRTUAL MOBILITY PROJECT
}

Ilona Buchem, Beuth University of Applied Sciences Berlin, Germany, Francesca Amenduni, Antonelle Poce, University degli Studio Roma Tre, Italy, Vlad Michaescu, Diana Andone, Universitatea Politehnica Timisoara, Romania, Gemma Tur, Santos Urbina, Universitat de les Illes Balears, Spain, Branislav Šmitek, University of Maribor, Slovenia

\section{Abstract}

This paper describes five different pilot case studies which show how miniMOOCs were integrated into study programs in higher education during COVID-19. The pilot case studies were conducted in five different countries (Germany, Italy, Spain, Romania and Slovenia) in the first quarter of 2020 as part of the Open Virtual Mobility project. Open Virtual Mobility project (OpenVM) is a three year (2017-2020) strategic partnership for innovation and the exchange of good practices founded by the European Erasmus+ program of the European Commission. One of the key outcomes of the Open Virtual Mobility project is the Open Virtual Mobility Learning Hub (OpenVM Learning Hub), an online learning environment for the development, assessment and recognition of virtual mobility skills in higher education. The OpenVM Learning Hub hosts a set of eight mini-MOOCs, each dedicated to a specific competency cluster. Based on small-scale pilots at the universities in the five countries, this paper describes the design of OpenVM mini-MOOC, spotlights different educational approaches for integrating MOOCs into study programs during COVID-19 and highlights diverse objectives, attitudes and expectations of educators who piloted the integration of the mini-MOOCs during the pandemic. The paper explores differences in integration of traditional MOOCs and mini-MOOCs and concludes with recommendations for embedding mini-MOOCs into academic programs in view of rapid (digital) transformations in higher education such as the one caused by COVID-19.

\section{Introduction}

In recent years, more and more attention has been directed towards integrating (or embedding) MOOCs into traditional, formal education, including curricula in study programs in higher education. This has been motivated by various economic (e.g. 
reduction of study fees and costs of production of online courses, increase in student retention, increase revenues for organisations), educational (e.g. to improve learning outcomes, enhance the quality of content, enable international collaboration, increase passage rates, reduce drop-out rates in MOOCs) and transformation (e.g. innovative educational models, internationalisation of education, cross-institutional collaborations, community outreach, broadening access to less educated audiences) oriented needs of educators and organisations (cf. Hollands \& Tirthali, 2014). The various approaches to integrating or embedding MOOCs into study programs and curricula have been termed as "MOOC 3.0", "hybrid MOOC” or “distributed flip" (cf. Sandeen, 2013; Caulfield, Collier, \& Halawa, 2013; Griffiths et al., 2014; Holotescu et al., 2014).

Instead of developing new MOOCs or using MOOCs as stand-alone learning experiences, MOOCs have been integrated into traditional courses to enhance the learning experience while embracing such methods as blended learning, flipped/inverted classroom, autonomous learning, international collaboration, peer-assessment and team-based learning. In this context, Dillenbourg et al. (2014) describe the integration of MOOCs into university education as "a shift from creating content to creating context". This implies new teaching roles, e.g. contextualising existing content, skilfully selecting and remixing existing content into a coherent story, providing guidance around the use of existing materials combined with teamwork and collaboration, reorganisation of infrastructure, e.g. rethinking infrastructure and facilities in view of the use of personal devices, growing importance of social learning, interaction and collaborative spaces, delivery of content and computer-based assessment, providing orchestration and analytic methods for educators, and the shift in focus from content-oriented activities to independent study and discovery, e g. inquiry-based models, exploring an existing body of knowledge, discovering new knowledge (Dillenbourg et al., 2014).

A number of different models and approaches have been applied in higher education institutions around the world to achieve a symbiosis between MOOCs and traditional higher education programs, including:

- Using MOOCs from popular MOOC platforms in alignment with regulatory frameworks. For example, Kulik and Kidimova (2017) describe the use of Coursera, EdX or Futurelearn at the National Research University Higher School of Economics in Moscow, Russia. The integration of MOOCs is embedded in a regulatory framework which specifies the credit transfer for MOOCs. In this case, the objective for integrating MOOCs into university curricula "is to improve the quality of our educational programs by including courses which allow to achieve 
specific tasks with limited resources" such as non-core courses, specialised courses in English, course with unique content (Kulik \& Kidimova, 2017; p.6).

- Creating Blended Massive Open Online Courses (bMOOC model). For example, Qusay and Norshuhada (2018) describe a blended MOOC model applied at the University of Tikrit in cooperation with University of Baghdad, Iraq. The blended MOOC model was implemented to foster interaction and communication among participants. This was achieved by integrating face-to-face interactions with MOOC components into a flexible model to enhance classroom learning which takes into consideration local culture and language. The learners could take an active role and the openness of the MOOC allowed a large number of participants around the world regardless of their level of education and location to learn together with on-campus students. This approach combined teacher-centred (classroom) and learner-centred (MOOC) methods.

- Adapting MOOCs to Small Private Online Courses (SPOC model). For example, Martinez and Campuzano (2015) report on adapting MOOCs into oncampus teaching, by using MOOCs in a blended, SPOC model but at the same time keeping the amount of hours for on-campus teaching to increase the quality of the educational experience. In this scenario, a blended learning approach using the flipped/inverted classroom model was applied in an on-campus environment with a smaller number of students than in MOOCs.

- Allowing students to choose MOOCs for self-study and/or as resources inside a traditional course. For example, Andone et al. (2015) describe the use of MOOCs available at popular MOOC platforms such as Coursera, Udemy, Udacity, edX, Khan Academy, Codecademy, FutureLearn, European MOOCs at Politehnica University of Timișoara, Romania (Andone et al., 2015). In one scenario students from the undergraduate course of web programming could choose and participate in different MOOCs as part of the blended learning course. In another scenario, MOOCs were chosen and used by students as external resources in the Instructional Technologies master course. In both scenarios students were given high autonomy for selecting, choosing and participating in MOOCs which matched their own learning needs.

- Synchronised integration of MOOCs as educational content/learning materials. For example, Ghadiri (2013) described how rich e-learning content, including video presentations from MIT MOOCs at edX can be integrated as learning materials into classroom teaching in the form of a blended model. The activities with integrated MOOC components included students watching minilecture videos of up to 10 minutes each and answering embedded questions online twice a week, reading assigned sections of the edX online textbook twice a week, 
solving edX problems and submitting answers online for automated grading by edX once a week, completing weekly edX online lab experiments and submitting answers online for automated grading by edX, watching edX videos of MIT faculty discussing different topics. This model was also described as synchronised integration of MOOCs into the face-to-face teaching by Holotescu et al. (2014).

Taking into account different approaches and models of MOOC integration, this paper describes five case studies in which mini-MOOCs were integrated into academic programs during the pandemic of COVID-19 in 2020. The spotlight of this paper is on the integration of MOOCs in times of (digital) transformations in higher education (such as the ones during the pandemic), during which fast solutions are required to provide online quality learning experiences to students. The five case studies describe the integration of miniMOOCs, given their specific affordances, as opposed to traditional MOOCs, which have been the dominant object of research.

\section{Context of the Study}

The five pilot case studies on the integration of mini-MOOCs were part of the Open Virtual Mobility project. Open Virtual Mobility project (OpenVM) is a three year (2017-2020) strategic partnership for innovation and the exchange of good practices founded by the European Erasmus+ program of the European Commission. One of the key outcomes of the Open Virtual Mobility project is the OpenVM Learning Hub (hub.openvirtualmobility.eu), an online learning environment for the development, assessment and recognition of virtual mobility skills in higher education. The OpenVM Learning Hub hosts a set of eight mini-MOOCs, each dedicated to a specific competency cluster.

The case studies presented in this paper are based on small-scale pilots at the universities in five countries (Germany, Italy, Spain, Romania and Slovenia) who are partner organisations or network partners in the project. In general, mini-MOOCs are smaller, shorter, cover less content and fewer skills than traditional MOOCs (Clark, 2016). OpenVM mini-MOOCs are designed to enable learners to learn in a flexible, self-directed and granular way, by easily aligning learning in the MOOC with other everyday activities. As described by Buchem, Poce, and Tur (2019), OpenVM mini-MOOCs are based on the principles of micro-learning design and aim to provide alignment of micro-learning objectives, micro-learning activities and micro-learning assessment with micro-credentials based on the Open Badges standard. OpenVM mini-MOOCs aim to support achievement, assessment and recognition of virtual mobility skills in eight competency areas. The eight competency areas were identified through a Group Concept Mapping research study (Rajagopal et al., 2020). 
The eight OpenVM mini-MOOCs are

- Media and digital literacy,

- Active self-regulated learning skills,

- Autonomy-driven learning,

- Networked learning,

- Intercultural skills and attitude,

- Interactive and collaborative learning in an authentic international environment,

- Open-mindedness, and

- Open virtual mobility knowledge.

OpenVM mini-MOOCs allow learners to learn at three levels, i.e. foundations, intermediate and advanced, providing learners with a number of e-assessment methods, including pre-assessment, formative and summative quizzes, e-portfolios and peerassessment. OpenVM Credentials (Open Badges) are issued upon successful completion of each level.

\section{Pilot Case Studies}

The eight OpenVM mini-MOOCs were piloted in the first quarter of 2020 at five universities involved in the project. The piloting phase overlapped with the COVID-19 pandemic and so the context for piloting changed from integration of mini-MOOCs into face-to-face on-campus courses to fully online scenarios. All OpenVM mini-MOOCs were facilitated. The role of the facilitators was to support learning activities, communicate important information to participants including schedules and deadline reminders as well as to support students in using technical components in the MOOCs, e.g. group formation, e-portfolio. Each university independently decided about the selection of mini-MOOCs to be piloted and the approach to integration into study programs. The decisions about integration of OpenVM mini-MOOCs included decisions about (a) synchronisation with the existing academic program including grading and credentialing, (b) number of levels to be piloted, (c) mode of participation (e.g. obligatory vs. voluntary). The presentation of case studies below follows five questions:

- Which OpenVM mini-MOOCs were piloted in which departments, study programs and modules/courses?

- What were the changes due to COVID-19 and implications for the integration of mini-MOOCs?

- What were the educational objectives for the integration of mini-MOOCs in each pilot?

- How were OpenVM mini-MOOCs integrated into existing study programs given the micro-learning format? 
Buchem, I., Amenduni, F., Poce, A. Michaescu, V., Andone, A., Tur, G., Urbina, S., \& Šmitek, B.

Integrating Mini-MOOCs into Study Programs in Higher Education during COVID-19. Five Pilot Case

Studies in Context of the Open Virtual Mobility Project

- What were the value added and the challenges from the perspective of educators?

\section{Pilot Case Study in Berlin, Germany}

The pilot case study in Berlin, Germany took place at the Beuth University of Applied Sciences. Following the COVID-19 pandemic, the summer semester 2020 at Beuth University of Applied Sciences in Berlin started later and teachers were encouraged to offer on-campus courses online. The "Collaborative Learning" mini-MOOC was integrated into "Learning Design" course in the bachelor study program "Digital Business (BSc.)" in Department I Economics and Social Sciences. The "Networked Learning” mini-MOOC was integrated into the "Learning Design" course in the online master study program Media Informatics n Department VI Informatics. All study programs in Department I were transformed from mostly face-to-face on-campus courses to online courses. This required a major makeover of the "Learning Design" course, which previously included weekly teamwork and collaboration on design tasks on campus following the Design Thinking approach. The shift to online format included changing to flipped classroom format with focus on autonomous learning with weekly reading assignments and quizzes. The online master study program Media Informatics did not have to be changed due to COVID-19 as it was already offered fully online before the pandemic. The joint objective for the two pilots to provide students with an opportunity to experience learning in a MOOC in an international setting and to learn the use of OERs, e-assessment including e-portfolio, group formation, and digital micro-credentials. In the bachelor study program, the majority of students reported they have never participated in any online course and never heard about MOOCs before. So, the specific objective for piloting in this course was to enable the first experience with MOOCs and enhance reflection about this form of learning. Another objective was to combine the MOOC experience with theory about learning design which was covered in the course. The specific objective for the Networked Learning MOOC in the online master program was for students to evaluate this miniMOOC using the expertise about learning designed covered by the course. Both miniMOOCs were a compulsory activity and were used both as stand-alone courses and as materials in the on-campus course. Students were required to complete three levels and obtain three badges. A specific number of points was assigned for completing each level. Students were given specific time-frames for participation in each level to allow a synchronised participation of students from different universities in activities which required group participation in intermediate and advanced levels. All students could learn at their own pace within specified time-frames and independent from other on-campus students. At the same time, both mini-MOOCs were used as resources in class to cover topics related to collaborative and networked learning. Both mini-MOOCs were used as examples for learning designs and were analysed by students together with the teacher in 
Buchem, I., Amenduni, F., Poce, A. Michaescu, V., Andone, A., Tur, G., Urbina, S., \& Šmitek, B.

Integrating Mini-MOOCs into Study Programs in Higher Education during COVID-19. Five Pilot Case

Studies in Context of the Open Virtual Mobility Project

interactive online-seminars. The micro-learning approach and the short duration of each mini-MOOC level allowed for a smooth integration of mini-MOOCs as part of self-study in each course and allowed students to experience learning in MOOCs. The key challenge was the coordination of times during group activities in the intermediate and advanced levels.

\section{Pilot Case Study in Rome, Italy}

From the beginning of March 2020, the health emergency caused by the spread of COVID19 imposed an immediate reorganisation of the CDM (Center for Museum Studies) postgraduate courses in "Museum Studies" at Roma Tre University. The post-graduate courses are aimed at developing professional, transversal and digital skills in future museum educators (http://centrodidatticamuseale.it/en/covid-19-emergency). The current mobilisation of the world of culture, in particular of the world of cultural heritage, encouraged the creation of specific teaching units aimed at understanding the current state of heritage institutions and at inventing possible strategies by designing ad-hoc educational activities. Therefore, the post graduate courses' managing staff prepared a series of units focused on increasing relevant distance learning opportunities to facilitate up-to-date attendance of the educational path started in February. OpenVM mini-MOOCs were aligned with our objectives to develop digital and transversal skills of students, who will be increasingly required to adopt digital tools to design educational paths in museum environments. Students could choose mini-MOOCs they were most interested in. Selfregulated learning skills were explained to students and the focus was on the ability to choose the most suitable learning path for own needs and goals. The MOOC attendance was not mandatory, but the attendance for each mini-MOOC was awarded with points. Participants were not familiar with MOOCs, so clarification was necessary. A presentation in Italian language for post-graduate students was prepared and uploaded to the LMS platform used in the courses. A 30-minute online lesson was organised with students two weeks before the start of intermediate and advanced levels. Students were required to read the presentation before the lesson and prepare their questions to the instructor. During the online session, participants were explained he different kinds of attendance in three levels. Since, intermediate and advanced levels had critical deadlines and steps to follow, most of the time was devoted to explaining these requirements.

\section{Pilot Case Study Ibiza, Spain}

OpenVM mini-MOOCs were offered for $\mathrm{PhD}$ students of the Institute of Educational Research and Innovation of the University of the Balearic Islands. There were 37 students from Spain and other South-American countries and the vast majority were doing the online PhD program in Educational Technology. The course was designed as an online 
Buchem, I., Amenduni, F., Poce, A. Michaescu, V., Andone, A., Tur, G., Urbina, S., \& Šmitek, B.

Integrating Mini-MOOCs into Study Programs in Higher Education during COVID-19. Five Pilot Case Studies in Context of the Open Virtual Mobility Project

course and thus no changes were needed due to the COVID-19 pandemic. However, the reflective texts submitted by students included references to the educational implications in future times after the pandemics. The learning objectives were to learn about OpenVM and to learn with MOOCs. The online course is designed as a short training to be done autonomously by $\mathrm{PhD}$ students. It consists of three main activities. The first one is about getting to know the concepts of virtual mobility, the implications of openness, and the skills that students develop while taking part in mini-MOOCs. Students were invited to read some research articles and to participate in an online forum with their personal experiences. The second activity was to participate in three selected mini-MOOCS at the foundational levels including the pre-assessment and the final quiz. The third activity was to reflect in the forum about the possibilities of OpenVM in higher education, their selfassessment and the implications for their future professional development and educational practice and research. The value added was both the content and the format of miniMOOCs. Presenting VM and OpenVM concepts introduced a new theme that had never been offered to students before. This was seen as a contribution to internationalisation. The context of autonomous learning in the MOOC is very relevant for the professional development of researchers in HE. The main challenge was using the English language, so the design of the course introduced reading material for Activity 1 in Spanish.

\section{Pilot Case Study in Kranj, Slovenia}

The mini-MOOC “Collaborative Learning” was piloted with third-year students of the Organization and Management of Information Systems program in Multimedia Systems. The course is part of the study program in the Faculty of Organisational Sciences in Kranj, which is a member of the University of Maribor. The content of this mini-MOOC was considered to be most appropriate for a students' work. Even if the content was not directly related to the content of the course, the new knowledge was considered beneficial for IT students, especially for their professional work in the future as well as a useful contribution for students' daily work. In Slovenia, COVID-19 demanded a rapid adjustment of the method of implementing the study process at all levels of education in the country. In the period before COVID-19, the Faculty of Organisational Sciences used blended learning methods and techniques in the educational process. The ratio of ex-cathedra and distance lectures is $50 \%-50 \%$. Lecturers at the faculty already had a lot of materials for distance education prepared before the COVID-19 period. The leap to full distance education, however, required a great deal of effort and adjustment. The use of OpenVM mini-MOOCs was therefore very welcome. The purpose of integrating the mini-MOOC was mainly to acquaint students with the concept of the MOOC itself. The content of the mini-MOOC was intended to supplement students' knowledge in educational methods. The miniMOOC was included in the course as one of the learning activities. Registration and 
Buchem, I., Amenduni, F., Poce, A. Michaescu, V., Andone, A., Tur, G., Urbina, S., \& Šmitek, B.

Integrating Mini-MOOCs into Study Programs in Higher Education during COVID-19. Five Pilot Case Studies in Context of the Open Virtual Mobility Project

completion of all activities were mandatory. Students were required to report on the work and the grade of their report on the mini-MOOC represented $10 \%$ of the final grade. The added value of working with the mini-MOOC was mainly in acquainting students with the OpenVM project, the mini-MOOC concept and a different way of working than in the course of Multimedia Systems. The challenges included the use of foreign languages and acquiring new knowledge in the field of collaborative learning.

\section{Pilot Case Study Timișoara, Romania}

After the COVID-19 lockdown was imposed on Timisoara, all university activities moved online. Students' progress was discussed via Zoom during regular classes and via email. The pilot took place during the Web 2.0 Technologies course with $4^{\text {th }}$ year Bachelor students from the Multimedia Specialization of the Faculty of Electronics, Telecommunications and Information Technology of the Politehnica University of Timisoara. All OpenVM mini-MOOCs were piloted, each student being required to choose two of them for piloting. All students had to complete pre-assessments and then follow each of the 3 levels of selected two mini-MOOCs. All students were required to write a maximum 800 words activity report in which they analysed the OpenVM Learning Hub, their experience in mini-MOOCs and the quality of the mini-MOOCs. Students had to prepare a report with screenshots from the course (e.g. activity completion, forum participation, errors, best parts of the course and badges obtained). The main objective was for the students to learn in mini-MOOCs and to gather important digital skills. Collaboration and active participation was encouraged. Students were asked to summarise and synthesise what they learned. Attention to details was encouraged when finding errors and bugs. The biggest change was the evaluation, which was done in Zoom. Each student presented their report and conclusions about the mini-MOOC, sharing their screen to showcase the most important points. From the educators' perspective, the piloting of the mini-MOOC helped the students to cope with the situation during the COVID-19 pandemic, especially at the beginning of the pandemic. The mini-MOOCs gave students a clear activity to focus on. A large number of courses and activities in the study program were not well prepared for moving online. A big challenge was to continue motivating students due to lack of interactivity in the mini-MOOCs as in that period of time, students in Timisoara were the only ones piloting. Also, because during piloting time some activities were unavailable, students could not receive all badges. This proved to be frustrating to students. OpenVM mini-MOOCs allowed to provide students the opportunity to develop digital and transversal skills required to face the challenges of the evolving and changing museums sector. It was important to provide instructions before students enrolled in miniMOOCs, especially regarding the intermediate and the advanced level requirements. 


\section{Conclusions}

The five pilot case studies presented above show that mini-MOOCs can be a beneficial contribution to on-campus courses especially in times of (digital) transformations such as during the pandemic. The main benefits seems to be the easy integration by educators to existing curricula as well as easy use for self-study by students. Given the micro-learning structure of mini-MOOCs, students can be provided with a short and simple way of experiencing learning with MOOCs. The reports of pilot studies show the diversity of approaches towards integrating mini-MOOCs to study programs. Following the five MOOC integration models proposed by Israel (2015), the pilot case studies both single MOOC and multiple MOOCs adoption, as well as synchronised, wrapped, blended and hybrid, models of integration.

The key benefits of integrating mini-MOOCs to study programs include allowing students to (a) experience self-directed/autonomous learning in MOOCs, (b) experience international collaboration and cultural differences, (c) diverse approaches to education and learning, (d) use diverse study materials, (e) reflect and demonstrate understanding of new concepts, and (f) share experiences with peers outside of the classroom. The key recommendations for the integration of mini-MOOCs include introducing students to selfregulated learning and explaining learning in the MOOC before the start of the MOOC, providing a well-structured and individual facilitation which encourages students to learn, share and reflect as well as creating links between on-campus and in-MOOC learning through "weaving” (Salmon, 2007) and "wrapping” (Israel, 2015).

\section{References}

Andone, D., Mihaescu, V., Ternauciuc, A., \& Vasiu, R. (2015). Integrating MOOCs in Traditional Higher Education. Proceedings of the European Stakeholder Summit on experiences and best practices in and around MOOCs, eMOOCs 2015, 18-20 May 2015, Mons, Belgium.

Buchem, I., Poce, A., \& Tur, G. (2019) Microlearning in MOOCs. A case study on designing engaging micro-learning experiences in the Media and Digital Literacy MOOC. Comunicación y Pedagogía: Microlearning, No. 315-316, 7-12. Retrieved from http://www.centrocp.com/comunicacion-y-pedagogia-315-316-microlearning

Buchem I., \& Konert J. (2020) Semantic Competency Directory for Constructive Alignment in Digital Learning Designs and Systems. In E. Popescu T. Hao, TC. Hsu, H. Xie, M. Temperini, W. Chen (eds.) Emerging Technologies for Education. SETE 2019. Lecture Notes in Computer Science, vol 11984. Springer, Cham. 
Caulfield, M., Collier, A., \& Halawa, S. (2013, October 6). Rethinking online community in MOOCs used for blended learning. Educause Review. [Blog post]. Retrieved from https://er.educause.edu/articles/2013/10/rethinking-online-community-in-moocsused-for-blended-learning

Clark, D. (2016). A Taxonomy of Massive Open Online Courses. Contemporary Educational Technology, 7(3), 223-240.

Dillenbourg, P., Fox, A., Kirchner, C., Mitchell, J., \& Wirsing, M. (2014). Massive open online courses: Current state and perspectives. Dagstuhl Manifestos, 4(1), 1-27.

Ghadiri, K. Q. (2013). The transformative potential of blended learning using MIT edX's $6.002 \mathrm{x}$ online MOOC content combined with student team-based learning in class. Environment, 8, 14.

Griffiths, R., Chingos, M., Mulhern, C., \& Spies, R. (2014). Interactive online learning on campus: Testing MOOCs and other platforms in hybrid formats in the University System of Maryland. ITHAKA S+R Report.

Hollands, F. M., \& Tirthali, D. (2014). MOOCs: Expectations and Reality. Full Report. New York: Teachers College, Columbia University. Retrieved from https://files.eric.ed.gov/fulltext/ED547237.pdf

Holotescu, C., Grossekc, G., Cretu, V., \& Naaji, A. (2014). Integrating MOOCs in blended courses. Proceedings of the International Scientific Conference of eLearning and Software for Education, Bucharest, 243-250.

Israel, M. J. (2015). Effectiveness of integrating MOOCs in traditional classrooms for undergraduate students. The International Review of Research in Open and Distance Learning, 16(5), 102-118.

Kulik, E., \& Kidimova, K. (2017). Integrating MOOCs in University Curriculum: HSE University Experience. Proceedings of EMOOCs 2017: Work in Progress Papers of the Experience and Research Tracks and Position Papers of the Policy Track.

Martinez, J., \& Campuzano, J. (2015). Accommodating MOOCs into HEI: is blendedlearning the solution? EUNIS Journal of Higher Education IT, Issue 2015/3; EUNIS2015 Congress Issue.

Qusay, A., \& Norshuhada, S. (2018). Effective design of blended MOOC in Iraq institutions. Journal of Education and Social Sciences, 9(2).

Rajagopal, K., Firssova, O., Op de Beeck, I., Van der Stappen, E., Stoyanov, S., Henderikx, P., \& Buchem, I. (2020). Learner skills in open virtual mobility. Research in Learning Technology, 28. 
Buchem, I., Amenduni, F., Poce, A. Michaescu, V., Andone, A., Tur, G., Urbina, S., \& Šmitek, B.

Integrating Mini-MOOCs into Study Programs in Higher Education during COVID-19. Five Pilot Case

Studies in Context of the Open Virtual Mobility Project

Salmon, G. (2007). 80:20 for E-Moderators. CMS Journal, 29. Retrieved from https://edoc.hu-berlin.de/handle/18452/7172

Sandeen, C. (2013). Integrating MOOCS into Traditional Higher Education: The

Emerging "MOOC 3.0" Era. Change: The Magazine of Higher Learning, 45(6), 34-39.

Retrieved from https://www.learntechlib.org/p/153130/

\section{Acknowledgements and Disclaimer}

Acknowledgements: This paper is based on the joint work and research conducted by partner organisations in the Erasmus+ Project Open Virtual Mobility, Cooperation for Innovation and the Exchange of Good Practices, Strategic Partnerships for higher education, (partially) founded by the European Union, Project Number 2017-1-DE01KA203-003494. Disclaimer: The creation of these resources has been (partially) funded by the ERASMUS+ grant program of the European Union under grant no. 2017-1-DE01KA203-003494. Neither the European Commission nor the project's national funding agency DAAD are responsible for the content or liable for any losses or damage resulting from the use of these resources. 